\title{
ANALISIS SIKAP DAN MUATAN PEMBELAJARAN IPA PADA TEMA EKOSISTEM KURIKULUM 2013 KELAS V SERTA POTENSI BUDAYA LOKAL PENDUKUNG PEMBELAJARAN
}

\author{
Laili Alfi Rahmatin ${ }^{1}$, A.A.I.N. Marhaeni ${ }^{2}$, I.M. Gunamantha ${ }^{3}$ \\ e-mail: alfi.rahmatin@pasca.undiksha.ac.id ${ }^{1}$; ngurah.marhaeni@pasca.undiksha.ac.id ${ }^{2}$; \\ md_gunamantha@yahoo.com ${ }^{3}$ \\ Program Studi Pendidikan Guru Sekolah Dasar, \\ Institut Pendidikan Nusantara Global, Indonesia, 83511
}

\begin{abstract}
Abstrak
Penelitian ini bertujuan untuk menganalisis dan mendeskripsikan nilai-nilai sikap dan muatan pembelajaran IPA serta potensi budaya lokal pendukungnya dalam kurikulum 2013 tema Ekosistem di kelas V sekolah dasar. Penelitian ini merupakan penelitian deskriptif kualitatif. Data dikumpulkan dengan menggunakan pencatatan dokumen dan wawancara. Analisis data dilakukan dengan metode deskriptif kualitatif. Informan dalam penelitian ini adalah budayawan, guru kelas 5 sekolah dasar, guru SBdP, dan orang tua siswa kelas 5.Hasil penelitian pada buku guru dan buku siswa tema Ekosistem menunjukkan bahwa:(1) sikap spiritual yang muncul adalah ketaatan beribadah, berprilaku syukur, dan toleransi dalam beribadah; (2) sikap sosial yang muncul adalah jujur, disiplin, tanggung jawab, santun, peduli dan percaya diri, (3) muatan pembelajaran IPA yang muncul adalah Lingkungan, alam semesta dan sumber daya alam, dan (4) nilai-nilai budaya lokal yang muncul dalam aktivitas anak kelas tinggi yang mendukung pengembangan nilai-nilai sikap pada tema Ekosistemyaitu, beberapa jenis permainan tradisional, cerita anak (satua), bernyanyi (magending), mengucapkan salam, dan kegiatan sembahyang (mebanten). Selanjutnya dari hasil temuan-temuan tersebut juga dihasilkan prototipe buku cerita anak berbasis budaya lokal pada tema Ekosistem kelas V sekolah dasar.
\end{abstract}

Kata kunci: budaya lokal, buku cerita, sikap.

\begin{abstract}
This research aims to analyze and describe the behavioral values and content of science learning as well as the local cultural potential of its support in the curriculum 2013 in the theme of Ecosystem at thefifth grade of elementary school. The reasearch was conducted under descriptive qualitative design. The data analysis were done by using descriptive qualitative. The subject of this research are cultural observer, teacher of grade 5 elementary school, SBdP teacher, ande the parents of grade 5 students. The research toward teachers and students book about Ecosystem reveals that: (1) the spiritual behaviors which appear are the obedience of worship, behave gratitude, and worship toleration. (2) the social behaviors which appear are being honest, discipline, responsible, well mannered, care and having self-confidence. (3) The content of science learning that apper are the environment, the univers, and natural resources. (4) the local cultural values which appear in the higher class activities that support the development of behavioral values in Ecosystem theme are, some traditional games, kids story (satua), singing (magending), greeting, and prayer activity (mebanten). Furthermore, the result of this research reveals prototype kids book stories based on local culture in the theme of Ecosystem in grade 5 elementary school.
\end{abstract}

Keywords: local culture, story book, attitude

\section{PENDAHULUAN}

Kurikulum 2013 adalah kurikulum berbasis kompetensi yang dirumuskan secara terpadu yang dimana kompetensi sikap,

pengetahuan dan keterampilan harus dikuasai oleh siswa. Didalamnya juga dirumuskan pembelajaran dan penilaian untuk memastikan 
ketercapaian kompetensi yang diinginkan. Kompetensi tersebut disampaikan dalam kompetensi inti yaitu Kompetensi inti I tentang sikap spiritual, Kompetensi Inti II tentang sikap sosial, Kompetensi III tentang pengetahuan, dan Kompetensi IV tentang keterampilan.

Salah satu perbedaan antara kurikulum 2013 dengan kurikulum sebelumnya adalah memiliki pedoman pegangan buku guru dan buku siswa yang disediakan secara langsung oleh pemerintah sebagai buku wajib ketika proses pembelajaran berlangsung. Pendekatan yang digunakan yakni pendekatan saintifik. Dimana pembelajaran saintifik merupakan pembelajaran yang berpusat pada siswa sehingga siswa dituntut untuk menemukan sendiri materi yang berkaitan dengan mata pelajaran tertentu (Fathurrahman, 2015:115).

Langkah yang harus diambil oleh setiap guru adalah mengintegrasikan sikap spiritual dan sikap sosial dalam pembelajaran, baik dalam perencanaan dan pelaksanaan pembelajaran.Pada penelitian yang dilakukan oleh Ariantini, dkk (2014) berpendapat bahwa impelementasi pengintegrasian sikap spiritual dan sikap sosial dalam perencanaan terletak pada komponen tujuan, langkah-langkah, dan penilaian pembelajaran. Pelaksanaannya dilakukan dengan cara memberikan motivasi atau dorongan, peringatan, arahan, teguran, penugasan, dan penguatan kepada siswa saat mengikuti kegiatan pembelajaran. Hambatannya terletak pada perencanaan dan pelaksaannya.

Buku-buku yang dikeluarkan oleh pemerintah, sudah berapa kali mengalami revisi, hal ini dilakukan dengan tujuan untuk pengembangan kurikulum dan mengimplementasikannya dalam kegiatan pembelajaran. Sejak diberlakukannya Kurikulum 2013, masih ditemukan adanya ketidaksesuaian isi buku dengan SKL, KI dan $\mathrm{KD}$, kemudian kedalaman materi yang tertuang dalam Buku Siswa masih perlu ditinjau dari karakteristik peserta didik karena jika ada yang dianggap kurang sesuai dengan karakteristik peserta didik di sekolah, hendaknya guru menindaklanjuti dengan memberikan tambahantambahan penjelasan seperlunya. Selain itu, dalam penerapan pendekatan yang digunakan, apakah sudah memfasilitasi peserta didik untuk melakukan kegiatan-kegiatan seperti yang diharapkan dalam pendekatan saintifik (dalam Sutrisno, 2016).

Materi yang masih bersifat ekspositori belum sesuai, ditambah denganKemendikbud melalui Peraturan Pemerintah nomor 23 tahun 2015 tentang penumbuhan budi pekerti meluncurkan sebuah gerakan GLS (Gerakan Literasi Sekolah)yang bertujuan untuk menumbuhkan sikap budi pekerti luhur kepada anak-anak melalui bahasa. Anak-anak pada usia Sekolah Dasar merupakan usia emas sehingga penting untuk menanamkan nilai-nilai budi pekerti luhur mereka. Sejalan hal tersebut (Setiawan: 2016) mengemukakan Gerakan literasi sekolah mempunyai tujuan untuk menumbuhkembangkan budi pekerti peserta didik melalui pembudayaan ekosistem literasi sekolah agar mereka menjadi pembelajar sepanjang hayat. Dimana. Sederhananya setiap anak diwajibkan membaca buku-buku bacaan cerita lokal dan cerita rakyat yang memiliki kearifan lokal dalam materi bacaannya sebelum pelajaran kelas dimulai.

Adapun materi yang disampaikan masih besifat ekspositori, jika dikaitkan dengan pembelajaran di kelas, materi yang bersifat ekspositori tidak sesuai jika dikaitkan dengan karakteristik anak di level konkrit. Sedangkan teori perkembangan kognitif menurut Piaget (dalam Santrock, 2014), bahwa dalam pemrosesan bahasa pada anak usia 11 tahun keatas, sudah mampu berpikir logis dan memiliki banyak gagasan ataupun konsep secara abstrak. Oleh karena itu, guru harus menginterpretasikan apa yang dikatakan oleh peserta didik dan merespon dengan memberikan wacana yang sesuai dengan tingkat perkembangan kognitif anak.

Penanaman nilai-nilai budi pekerti luhur ini penting dilakukan sejak usia dini sebab proses pendidikan sejatinya bukan hanya untuk mencetak manusia yang cerdas secara intelektual, tapi juga cerdas emosional dan spiritual. Menurut Vygotsky dalam Marhaeni (2013) pemerolehan pengetahuan seorang berasal dari sumber sosial diluar dirinya atau lingkungannya. Harus diakui salah satu 
kekeliruan besar dalam pendidikan kita adalah sangat mengedepankan kecerdasan intelektual, namun mengenyampingkan pelajaran yang mengandung nilai-nilai moral.

Masuknya globalisasi membawa dampak positif dan negatif bagi pendidikan, berbagai dampak positif seperti penyebaran informasi yang cukup cepat, inovasi dalam metode dan model pembelajaran, budaya lokal apabila tidak dikemas dengan baik akan terpinggirkan, bahkan siswa cenderung mengagungkan budaya luar yang lebih modern dibandingkan dengan melestarikan budaya lokal, sehingga dipandang perlu menumbuhkan budaya lokal tersebut dalam pembelajaran di sekolah. Namun cerita bermuatan budaya lokal yang dapat mengembangkan sikap anak sesuai K-13 belum teridentifikasi.

Menurut Taro dalam Guna (2014:47) "dunia anak yang seharusnya diisi dengan aktivitas bermain, mendengar cerita, dan juga bernyanyi". Hal ini senada dengan yang disampaikan oleh Gunarti (2015:53) "bercerita adalah suatu kegiatan yang dilakukan seseorang untuk menyampaikan suatu pesan, informasi atau sebuah dongeng belaka, yang bisa dilakukan dengan menggunakan alat peraga dan tanpa alat peraga.

Cerita secara faktual erat sekali hubungannya dengan pembentukan karakter, bukan saja karakter manusia secara individual, tetapi juga karakter manusia dalam sebuah bangsa. Kekuatan karakter akan terbentuk dengan sendirinya jika ada dukungan dan dorongan dari lingkungan sekitar. Peran keluarga, sekolah, dan masyarakat sangat dominan dalam membangun kekuatan karakter (Gunawan: 2012), Ada sejumlahcara yang mungkindapatditerapkansebagaipendidikan moral anak. Salah satucaradengan mencontohkan perbuatan dan tingkahlaku yang baik dan mendorong anak untuk meneladani hal tersebut dan anak akan belajar dengan senang METODE

Jenis Penelitian yang dilaksanakan merupakan penelitian deskriptif kualitatif. Penelitian Deskriptif adalah suatu penelitian yang berusaha mendeskripsikan suatu fenomena atau peristiwa secara sistematis dan apa adanya. dan cepat paham bila dimulai dengan mendongeng (Husni: 2012). Cerita anak adalah sesuatu yang bermakna bagi anak apabila dapat meberikan kemanfaatan (Zubaidah: 2013). Namun belakangan ini kebiasaan mendongeng atau bercerita mulai berkurang. Pesatnya perkembangan teknologi media seperti sekarang secara tidak disadari telah mengubah perilaku anak-anak didalam kesehariannya. Aktivitas mendongeng tidak lagi dibutuhkan dalam ranah pendidikan anak-anak mengingat pembelajaran anak memalui aktivitas mendongeng sudah cukup dapat digantikan dengan media yang namanya televisi.

Selain itu cerita yang sesuai dengan muatan pembelajaran juga sulit dicari padahal dalam pembelajaran bahasa melalui mendongeng adalah pintu masuk dalam pembelajaran. Serta model pembelajaran yang sesuai dengan karakter berbasis kurikulum 2013 dan bahan ajarnya yaitu buku cerita anak berbasis budaya lokal belum banyak tersedia. Selain itu belum teridentifikasinya secara jelas mengenai sikap spiritual (KI-1) dan sikap sosial (KI-2) pada muatan pembelajaran yang ada.

Penelitian seperti itu sebelumnya sudah pernah dilakukan oleh Ni Kadek Ayu Windari, dkk hanya saja penelitian mereka baru sampai menganalisis pembelajaran sikap dan literasi dini di kelas awal. Oleh karena itu ada tindak lanjut untuk menganalisis kembali tentang kajian mengenai sikap dan muatan pembelajaran pada kelas tinggi, khususnya di kelas 5 pada tema Ekosistem, serta kajian nilai-nilai budaya lokal yang mendukung untuk menghasilkan sebuah prototipe teoritik buku cerita anak yang nantinya dapat dikembangkan menjadi sebuah buku cerita anak, yang bisa difungsikan sebagai suplemen buku pelajaran yang dapat mengembangkan nilai sikap anak sesuai dengan pembelajaran tema Ekosistem kelas 5 sekolah dasar Kurikulum 2013.

Subjek penelitian adalah pihak-pihak yang dijadikan sebagai sampel dalam sebuah penelitian. Subjek penelitian berupa benda yakni buku guru dan buku siswa pembelajaran tematik tema Ekosistem kelas Vkurikulum 2013. 
Subjek penelitian dari informan adalah: Budayawan (3 orang), Guru kelas V (3 orang), Guru Seni Budaya dan Prakarya (SBdP) (3 orang), dan Orang tua siswa kelas V (3 orang).

Variabel-variabel dalam penelitian ini adalah: (1) Nilai - nilai sikap spiritual, (2) sikap sosial, (3) ruang lingkup materi muatan pembelajaran IPA dan (3) budaya lokal dalam kehidupan anak kelas tinggi sekolah dasar. Metode pencatatan dokumen dan wawancara digunakan untuk mengumpulkan data tentang muatan nilai-nilai sikap dan muatan pembelajaran IPA pada kurikulum 2013. Dokumen yang digunakan meliputi buku guru, buku siswa tema Ekosistem kelas V Sekolah Dasar. Metode wawancara digunakan dengan tujuan menggali informasi dari narasumber (budayawan, guru kelas V, guru SBdP, dan HASIL DAN PEMBAHASAN

Penelitian ini menghasilkan data-data melalui pencatatan/studi dokumen yang termuat pada buku guru dan buku siswa tentang nilainilai sikap dan muatan pembelajaran IPA yang terkandung dalam buku kelas V Sekolah Dasar tema Ekosistem, dan data untuk budaya lokal Bali yang dikumpulkan melalui wawancara dengan berbagai narasumber antara lain, budayawan, guru SBdP, guru kelas, dan orang tua siswa. Hasil pengumpulan data tersebut setelah ditabulasi selanjutnya dianalisis, sehingga data-data yang diperoleh melalui pencatatan dokumen dan wawancara dapat menjadi dasar perancangan prototipe buku cerita anak berbasis budaya lokal Bali. Adapun hasilhasil penelitian yang diperoleh berdasarkan hasil analisis dan wawancara adalah sebagai berikut.

Sikap spiritual terdiri atas beberapa aspek sikap, diantaranya 1) ketaatan beribadah, 2) berperilaku syukur, 3) berdoa sebelum dan sesudah berkegiatan, dan 4) toleransi dalam beribadah. Berdasarkan hasil analisis, ditemukan tiga aspek yang muncul pada tema Ekosistem yakni ketaatan beribadah, berperilaku syukur dan toleransi dalam beribadah. Aspek berperilaku syukur memiliki frekuensi kemunculan lebih banyak secara signifikan dibandingkan dengan aspek lain. Hal tersebut menunjukkan bahwa berperilaku syukur orang tua siswa kelas $\mathrm{V}$ sekolah dasar) tentang nilai - nilai budaya lokal berupa aktivitas anak kelas awal yang mendukung nilai spiritual dan sosial pada pembelajaran tematik terpadu dengan tema Ekosistem kelas V Sekolah Dasar

Analisis data yang dilakukan dalam penelitian ini yaitu metode analisis deskriptif kualitatifdigunakan untuk menjustifikasi pencatatan dokumen mengenai nilai-nilai sikap dan muatan pembelajaran IPA yang terdapat pada buku guru dan buku siswa pada tema Ekosistem di kelas V Sekolah Dasar. Mengklasifikasi hasil wawancara dengan narasumber budayawan, guru kelas, guru SBdP, dan orang tua siswa untuk dapat mengetahui dimensi nilai budaya lokal yang sesuai dengan nilai sikap spiritual dan sosial pada tema Ekosistem kelas V Sekolah Dasar.

mendapat penekanan pada tema Ekosistem di kelas V sekolah dasar.

Nilai sikap sosial terdiri atas beberapa aspek sikap diantaranya; 1) jujur, 2) disiplin, 3) tanggung jawab, 4) santun, 5) peduli, dan 6) percaya diri.Analisis yang dilakukan terhadap buku guru dan buku siswa kelas $\mathrm{V}$ tema Ekosistem menghasilkan beberapa temuan muatan nilai-nilai sikap sosial. Berdasarkan hasil analisis, ditemukan enam aspek sikap sosial muncul pada tema Ekosistem yakni jujur, disiplin, tanggung jawab, santun, peduli dan percaya diri. Berdasarkan kemunculan, aspek jujur dan percaya diri lebih mendominasi daripada yang lainnya. Hal ini menunjukkan bahwa aspek sikap jujur dan percaya diri mendapatkan penekanan pada tema Ekosistem. Namun, untuk aspek sikap sosial lainnya yakni disiplin, santun, dan peduli tetap diperhitungkan.

Hasil penelitian ini juga mengungkap muatan pembelajaran IPA pada tema Ekosistem kelas V sekolah dasar. Hasil analisis terhadap buku guru dan buku siswa, menunjukkan bahwa muatan pembelajaran IPA yang muncul yakni lingkungan, alam semesta, dan sumber daya alam.

Selain muatan nilai sikap dan muatan pembelajaran, hasil lain dari penelitian ini adalah muatan budaya lokal sebagai penerapan pembelajaran SD kelas tinggi yang berupa 
permainan tradisional, cerita (satua), nyanyian (gending), mengucapkan salam tradisional Bali, dan kewajiban sembahyang (mebanten).

Berdasarkan wawancara yang dilkakukan, diperoleh jenis permainan tradisional bali untuk anak kelas tinggi antara lain Makeringkeringan, Megala-galaan, Mecingklak, Main Tali, Tembing,Dengkleng, Meong-meongan, Tajog, Gangsing, Goak-goakan, Kering Ngkeb, dan Main kartu,

Untuk jenis cerita anak (satua) untuk anak kelas tinggi berdasarkan hasil wawancara antara lain cupak gerantang, I belog, men tiwas lan men sugih, I bawang teken I kesuna, Tuwung Kuning, Pan Balang Tamak, I Siap Selem, I Belog, dan Jayaprana.

Sementara untuk nyanyian (gending) untuk anak SD kelas tinggi yang diperoleh berdasarkan hasil wawancara antara lain ketut garing, bebek putih jambul, meong-meong, guak maling taluh, made cenik, sumping waluh, ratu anom, pupuh pucung, pupuh mijil. juru pencar, jenggot uban, pupuh maskumambang, dan pupuh ginada.

Untuk aspek budaya lokal lainnya yakni salam yang biasa diucapkan anak SD kelas tinggi berdasarkan hasil wawancara antara lain Om Swastiastu, Rahajeng semeng, Selamat Pagi, dan selamat siang.

Kebiasaan sembahyang (mebanten) untuk anak SD kelas tinggi yang diperoleh berdasarkan hasil wawancara antara lain mebanten ajengan/banten ketipat. canang, mebanten saiban, mebanten wedang, masegeh dan mebanten rahinan (purnama, tilem, saraswati, dll)

Berdasarkan analisis yang dilakukan terhadap buku guru dan buku siswa dalam pembelajaran tematik tema Ekosistem di kelas $\mathrm{V}$, ditemukan nilai sikap spiritual yang termuat yaitu ketaatan beribadah dan berperilaku syukur. Dalam Permendikbud No. 21 tahun 2016, tertera bahwa sikap spiritual mencakup perilaku menerima, menjalankan, dan menghargai ajaran agama yang dianutnya. Ketaatanberibadah dan berperilaku syukur merupakan nilai-nilai fundamental dalam cerminan sikap spiritual seseorang. Muatan nilai-nilai sikap spiritual tersebut merupakan wujud sikap meyakini adanya Tuhan melalui agama yang dipeluknya, serta menghayati dan mengamalkan ajarannya dalam kehidupan sehari. Ketaatanberibadah dan berperilaku syukur merupakan nilai-nilai fundamental dalam cerminan sikap spiritual seseorang. Muatan nilai-nilai sikap spiritual tersebut merupakan wujud sikap meyakini adanya Tuhan melalui agama yang dipeluknya, serta menghayati dan mengamalkan ajarannya dalam kehidupan sehari-hari. Perilaku syukur, taat beribadah dan toleransi dalam beribadah merupakan tanda seseorang memiliki kematangan dalam beragama, dan hal tersebut mencerminkan yang bersangkutan memiliki sikap spiritual yang baik dalam dirinya. Selanjutnya berdasarkan hasil wawancara terhadap narasumber, ditemukan adanya aspekaspek budaya lokal yang dekat dengan aktivitas anak kelas tinggi dan perlu diimplementasikan dalam bentuk cerita anak. Ditemukan pula adanya kandungan nilai-nilai spiritual yang dapat dituangkan ke dalamnya.

Aspek budaya lokal yang menunjukkan keterkaitan dengan nilai sikap spiritual tersebut adalah cerita (satua). Ada beberapa judul cerita (satua) yang dapat memuat sikap taat beribadah dan berperilaku syukur yakni I bawang lan I kesuna, Men Sugih jak Men Tiwas dan Cupak Gerantang. Ditemukan pula salah satu aktivitas budaya lokal lain yang sesuai dengan nilai sikap spiritual yakni aktivitas mebanten.Menurut keterangan dari seluruh narasumber, nilai sikap spiritual dalam aktivitas mebanten canang sari (sehari-hari), dan mebanten rahinan (purnama, tilem, saraswati) merupakan wujud ketaatan beribadah dan berperilaku syukur kepada Tuhan yang maha esa atas berkah yang dimiliki-Nya. Selanjutnya untuk aspek toleransi dalam beribadah dapat muncul dalam aktifitas mengucapkan salam budaya lokal, dimana salam yang digunakan adalah Om swastiastu untuk yang agama Hindu dan ucapan salam Nasional (selamat pagi, siang dan sore) jika bertemu orang lain atau beragama lain.

Selanjutnya ditemukan pula nilai-nilai sikap sosial yang muncul pada tema Ekosistem yang memilki keterkaitan dengan aspek budaya lokal. Adapun nilai sikap sosial yang termuat 
yaitu jujur, disiplin, tanggung jawab, santun, peduli, dan percaya diri.

Sikap sosial yang termuat dalam Kurikulum 2013 di kelas V mengacu pada Permendikbud No. 21 tahun 2016 ditunjukkan melalui perilaku jujur, disiplin, tanggung jawab, gotong royong, santun, peduli, dan percaya diri dalam berinteraksi dengan keluarga, teman, guru, dan tetangganya serta cinta tanah air Tentunya hal ini menunjukkan bahwa buku guru dan buku siswa telah memuat sikap sosial sebagai mana yang diharapkan secara yuridis.

Hasil wawancara terhadap narasumber menunjukkan adanya aspek-aspek budaya lokal yang dekat dengan aktivitas anak kelas tinggi dan perlu diimplementasikan dalam bentuk cerita anak (satua) seperti I Belog, Bawang Kesuna, dan Lutung jak Kakua memaling Isen. Ditemukan pula adanya kandungan nilai-nilai sosial yang dapat dituangkan ke dalamnya. Selain itu terdapat aktivitas budaya lokal lainnya yang dapat memunculkan nilai sikap sosial berdasarkan keterangan narasumber yakni permainan tradisional seperti megala-gala, gowak-gowakan, dan meong-meongan. Kemudian aktivitas bernyanyi (gending) seperti ratu anom, pupuh pucung, dan juru pencar. Juga pada aktivitas mengucap salam seperti panganjali/paramasanthi maupun salam daerah bali yakni rahajeng semeng/rahajeng wengi. Hal ini menunjukkan bahwa, latar budaya lokal memiliki andil dalam pembentukan sikap sosial seseorang.

Purnell's (dalam Sudana \& Astawan, 2013), mendefinisikan sains/IPA sebagai pengetahuan manusia yang luas yang didapatkan dengan observasi dan eksperimen yang sistematik, serta dijelaskan dengan bantuan aturan-aturan, hukum-hukum, prinsipprinsip, teori-teori dan hipotesis-hipotesis. Pembelajaran IPA/sains pada akhirnya harus memenuhi tiga hasil yakni IPA sebagai produk (berkenaan dengan konsep dan implementasinya), IPA sebagai sikap (berkenaan dengan sikap ilmiah), dan IPA sebagai proses (berkenaan dengan metode/pendekatan ilmiah yang digunakan). Hal-hal tersebut dapat diperoleh melalui pengalaman mempelajari muatan pembelajaran
IPA. Analisis terhadap kemunculan kompetensi dan materi pembelajaran IPA sebagaimana yang telah diuraikan dalam hasil penelitian, menunjukkan adanya muatan pembelajaran IPA yang muncul dalam pembelajaran tema Ekosistem yakni lingkungan, alam semesta, dan sumber daya alam.

Hasil dari wawancara terhadap narasumber menunjukan adanya aspek-aspek budaya lokal yang dekat dengan aktivitas anak kelas tinggi dan mampu memuat muatan pembelajaran IPA di pada tema Bangga Ekosistem antara lainmendengarkan satuayakni Siap Selem, Bawang Kesune, Ketimun Emas, I Belog, Cupak Gerantang, I Lutung I Kekua, dan Ni Tuwung Kuning, dan permainan tradisional yakni Tajog, gangsing, kering ngkeb, mecingklak, dan bekel.

Hasil wawancara ini memunculkan pemahaman bahwa keterkaitan antara nilai sikap dan muatan pembelajaran IPAsertaunsur budaya lokal bali cukup erat dengan aktivitas anak SD kelas tinggi. Maka dari itu, selain mendengarkan satua, aktivitas bermain permainan tradisional, bernyanyi (gending), dan mengucapkan salam perlu dimasukkan ke dalam buku cerita anak berbasis budaya lokal bali yang diharapkan mampu menjadi suplemen konten literasi mendampingi buku pelajaran kurikulum 2013

Berdasarkan hasil penelitian dan pembasahan di atas, dapat dirancang sebuah keterkaitan nilai-nilai sikap dan muatan pembelajaran IPA dengan budaya lokal untuk pembelajaran kelas V tema Ekosistem. Adapun temuan tersebut diuraikan sebagai berikut: 1) nilai-nilai sikap spiritual yaitu ketaatan beribadah berperilaku syukur, dan toleransi dalam beribadah, 2) nilai-nilai sikap sosial yaitu jujur, disiplin, tanggung jawab, santun, peduli dan percaya diri, 3) muatan pembelajaran IPA yaitu lingkungan, alam semesta, dan sumber daya alam, dan 3) Muatan budaya lokal yang meliputi berbagai jenis permainan tradisional meliputi Makering-keringan (kering keb), Megala-galaan, Mecingklak, Main Tali, Tembing (dengkleng), meong-meongan, tajog, gangsing, dan magoak-goakan. Mendengarkan cerita meliputi cerita Maya denawa, 
mengkuwuk, Kunang-kunang ngaba api, cupak gerantang, I belog, men tiwas lan men sugih, I bawang teken I kesuna, Tuwung Kuning, Pan Balang Tamak, I Siap Selem, I Kekua. lutung teken kambing, dan Pedanda Baka, dan Kebo iwa. Aktivitas bernyanyi/magending diantaranya ketut garing, bebek putih jambul, meong-meong, guak maling taluh, made cenik, sumping waluh, ratu anom, pupuh pucung, pupuh mijil. juru pencar, jenggot uban, pupuh maskumambang, dan pupuh ginada. Jenis
Salam budaya lokal yaitu Om Swastiastu, Rahajeng semeng, Selamat Pagi, dan selamat siang. Aktivitas Beribadah (Mebanten) yaitu mebanten ajengan/banten ketipat. canang, mebanten saiban, mebanten wedang, masegeh dan mebanten rahinan (purnama, tilem, saraswati, dll)

Adapun keterkaitan antar nilai-nilai sikap dan muatan pembelajaran IPA dengan nilai-nilai budaya lokal pendukungnya, disajikan dalam tabel 1. berikut.

\section{Tabel 1. Keterkaitan Nilai-nilai SIkap Dengan Budaya Lokal Untuk TemaEkosistem di Kelas V Sekolah Dasar}

\begin{tabular}{|c|c|c|c|}
\hline No & Aspek & Temuan & Budaya Lokal Yang mendukung \\
\hline \multirow[t]{3}{*}{1} & \multirow[t]{3}{*}{ Nilai Sikap Spiritual } & Ketaatan Beribadah & $\begin{array}{ll}\text { Kewajiban bersembahyang/ mebanten seperti: } \\
\text { - } & \text { Mebanten saiban } \\
- & \text { Mebanten canang } \\
\text { - } & \text { Sembahyang Purnama Tilem } \\
- & \text { Saraswati } \\
- & \text { Mebanten segehan }\end{array}$ \\
\hline & & Berprilaku Syukur & $\begin{array}{l}\text { Bawang Kesune, Ketimun Emas, Men Sugih jak } \\
\text { Men Tiwas, Cupak Gerantang }\end{array}$ \\
\hline & & $\begin{array}{l}\text { Toleransi } \\
\text { beribadah }\end{array}$ & $\begin{array}{l}\text { Mengucapkan salam budaya lokal seperti Om } \\
\text { Swastiastu }\end{array}$ \\
\hline \multirow[t]{6}{*}{2} & \multirow[t]{6}{*}{ Nilai Sikap Sosial } & Jujur & $\begin{array}{l}\text { - Cerita (Satua) seperti I Belog, Bawang Kesuna, } \\
\text { Lutung Jak Kakua memaling Isen } \\
\text { - Permainan tradisional seperti Mecingklak, } \\
\text { Gangsing, dan Bekel }\end{array}$ \\
\hline & & Disiplin & $\begin{array}{l}\text { Permainan tradisional makering-keringan, gowak- } \\
\text { gowakan, dan bermain kartu. }\end{array}$ \\
\hline & & Tanggung Jawab & $\begin{array}{l}\text { Permainan tradisional megala-gala, gowak-gowakan, } \\
\text { dan meong-meongan. }\end{array}$ \\
\hline & & Santun & $\begin{array}{l}\text { Aktvitas mengucapkan salam yakni panganjali } \\
\text { maupun salam nasional rahajeng semeng/ rahajeng } \\
\text { wengi }\end{array}$ \\
\hline & & Peduli & $\begin{array}{l}\text { - Cerita (satua) seperti Jayaprana dan Cupak } \\
\text { Gerantang } \\
\text { - Permainan tradisional seperti meong-meongan, } \\
\text { megala-gala dan gowak-gowakan }\end{array}$ \\
\hline & & Percaya Diri & $\begin{array}{l}\text { Bernyanyai (megending) seperti ratu anom, pupuh } \\
\text { pucung, dan juru pencar. }\end{array}$ \\
\hline 6 & $\begin{array}{l}\text { Muatan Pembelajaran } \\
\text { IPA }\end{array}$ & $\begin{array}{l}\text { lingkungan, alam } \\
\text { semesta, dan } \\
\text { daya alamber }\end{array}$ & $\begin{array}{l}\text { - Cerita (satua) anak seperti Siap Selem, Bawang } \\
\text { Kesune, Ketimun Emas, I Belog, Cupak } \\
\text { Gerantang, Kancil dan Buaya, I Lutung I } \\
\text { Kekua, dan Ni Tuwung Kuning. } \\
\text { Permainan tradisional anak seperti tajog, } \\
\text { gangsing, kering ngkeb, mecingklak dan bekel } \\
\text { Nyanyian (megending) anak seperti meong- } \\
\text { meong, dadong dauh dan bebek jambul putih }\end{array}$ \\
\hline
\end{tabular}

\section{KESIMPULAN}


Berdasarkan hasil analisis dan pembahasan maka dapat ditarik simpulan sebagai berikut.

Pertama, nilai-nilai sikap spiritual yang termuat dalam pembelajaran kelas $\mathrm{V}$ pada tema Ekosistem adalah ketaatan beribadah berperilaku syukur dan toleransi dalam beribadah, dan nilainilai sikap sosial yang termuat adalah jujur, disiplin, tanggung jawab, santun, peduli, dan percaya diri. Muatan pembelajaran yang termuat dalam pembelajaran kelas $\mathrm{V}$ pada tema Ekosistem antara lain; BI (teks syair \& pantun, teks teks paparan, dan teks penjelasan), PKn (makna keberagaman personal, sosial, dan kultural), Matematika (bilangan geometri dan pengukuran sederhana) IPA (lingkungan, alam semesta, dan sumber daya alam), IPS (kehidupan manusia dan kelembagaan sosial, ekonomi, pendidikan dan budaya masyarakat dan bangsa Indonesia), SBdP (apresiasi dan kreasi/rekreasi karya seni musik dan seni rupa), dan PJOK (gerak dasar lari/lompat, gerak dasar bela diri dan gerak dasar ritmik/tari bertema budaya daerah dan nasional).

Kedua, aktivitas budaya lokal yang harus termuat dalam buku cerita anak yang dapat digunakan untuk menanamkan nilai-nilai sikap dan membelajarkan muatan pembelajaran adalah 1) permainan tradisional: meicngklak, gangsing, bekel, makering-keringan, gowakgowakan, kartu, megala-gala, meong-meongan, kering ngkeb, tajog, dengkeleng, gobak sodor, tembing, dan main tali; 2) mendengarkan satua: Bawang lan Kesuna, I belog, Cupak gerantang, Jayaprana, I Men sugih lan men tiwas, dan I lutung jak I kakua memaling isen, Siap Selem, Pan Balang Tamak dan Tuwung Kuning; 3) bernyanyi/magending: juru pencar, made cenik, ratu anom, putri cening ayu, dan pupuh pucung; 4) mengucapkan salam: panganjali umat (om swastyastu), rahajeng (semeng/wengi), dan 5) kewajiban sembahyang/mebanten: mebanten canang sari (sehari-hari), dan mebanten rahinan (purnama, tilem, saraswati, dll).

Ketiga, berdasarkan hasil penelitian dan pembahasan, dapat disusun sebuah prototipe buku cerita anak berbasis budaya lokal pada tema Ekosistem kelas V sekolah dasar.

\section{SARAN}

Berdasarkan simpulan penelitian yang telah dipaparkan, maka dapat diajukan beberapa saran sebagai berikut.

Bagi pendidik, disarankan mampu mengembangkan teori pendidikan khususnya tentang peningkatan kualitas pembelajaran sikap dan muatan pembelajaran siswa kelas V sekolah dasar dengan menggunakan cerita anak bermuatan lokal temaEkosistem.

Bagi siswa, disarankan agar lebih meningkatkan perhatian minat dalam mendengarkan cerita anak guna menumbuhkan motivasi belajar yang akan membantu siswa dalam pengembangan sikap maupun muatan pembelajaran di sekolah dasar.

\section{DAFTAR PUSTAKA}

Ariantini,N. P., Suandi, I. N., \& Sutama, I. M. 2014. Impelementasi Pengintegrasian Sikap Spiritual Dan Sikap Sosial Dalam Pembelajaran Bahasa Indonesia Berbasis Kurikulum 2013 Di Kelas VII SMP Negeri $1 \quad$ Singaraja. E-jurnal. Program pascasarjana UNDIKSHA program studi Bahasa. Volume 3 tahun 2014.

Fathurrahman, M. 2015. Paradigma Pembelajaran Kurikulum 2013 Strategi Alternatif Pembelajaran Kurikulum 2013 Strategi Pembelajaran di Era Global. Yogyakarta: Kalimedia.

Guna, I G M. 2014. Made Taro Mendongeng dan Bermain Sepanjang Waktu. Yogyakarta : Media Kreatifitas Yogyakarta.

Gunarti, W. 2015. Metode Pengembangan Perilaku dan Komponen Dasar Anak Usia Dini. Jakarta: Universitas Terbuka.

Gunawan. I. 2016. Pendidikan Karakter. Malang: Universitas Negeri Malang.

Husni, R. Dan Maila. 2012. The Use of Stories as Moral Education fo Young Children. International Journal. of Social Sciences and Humanity, Vol 2 No.6 November 2012

Marhaeni, A.A.I.N. 2013. Landasan dan Inovasi Pembelajaran.Singaraja: Universitas Pendidikan Ganesha.

Kementerian Pendidikan dan Kebudayaan. 2013. Permendikbud No 21 Tahun 2016. tentang Standar Isi Pendidikan Dasar Dan Menengah. 
Santrock, J. W. 2014. Psikologi Pendidikan Edisi 5. Jakarta: Salemba Humanika

Setiawan, R. (2016). Gerakan Literasi Sekolah. Jakarta: Satgas Gerakan Literasi Sekolah Dirjen Pendidikan Dasar dan Menengah.

Sudana dan Astawan. 2013. Pendidikan IPA SD. Singaraja: Undiksha Singaraja.

Sutrisno. 2016. Menyongsong Kurikulum 2013 Jilid

Dua. http://www.pontianakpost.co.id/menyongs ong-kurikulum-2013-jilid-dua. Diunduh pada tanggal 28 Desember 2016.

Windari. N. K. A. 2015. Metode Pengembangan Prilaku dan Komponen Dasar Anak Usia Dini. Jakarta : Universitas Terbuka

Zubaidah. E. 2013. Pemilihan Nilai Karakter dalam Cerita Anak dan Tehnik Penceritaannya. Jurnal. Pendidikan Anak. Vol. II edisi 2 Desember 2013 